\title{
ARRANJO EDUCACIONAL DA REGIÃO DA GRANDE FLORIANÓPOLIS: UM ESTUDO DE CASO
}

\section{ARTIGO ORIGINAL}

BORGES, José Carlos ${ }^{1}$

FELICIANO, Felipe Kupka ${ }^{2}$

WILLERDING, Inara Antunes Vieira ${ }^{3}$

LAPOLLI, Édis Mafra ${ }^{4}$

BORGES, José Carlos. Et al. Arranjo Educacional da região da grande Florianópolis: Um estudo de caso. Revista Científica Multidisciplinar Núcleo do Conhecimento. Ano 05, Ed. 09, Vol. 09, pp. 35-45. Setembro de 2020. ISSN: 24480959, Link de acesso: https://www.nucleodoconhecimento.com.br/educacao/arranjoeducacional

\section{RESUMO}

O mundo vem sofrendo grandes transformações, em questão de dias o que é inovador torna-se obsoleto. Com os modelos educacionais não é diferente, a educação tem, não somente a necessidade de mudar, mas o dever. Nos últimos anos frequentemente se discute educação, porém muitas vezes se tem como resultado mais do mesmo, mais conteúdo, teoria e modelos educacionais e na maioria das vezes, modelos específicos para um determinado município ou até mesmo escola. É a hora de repassar a educação de forma inovadora, sistêmica e cooperativa, buscar soluções em conjunto para melhor equidade e qualidade do ensino. O Arranjo do

\footnotetext{
${ }^{1}$ Especialista em Gestão e Tutoria da EAD.

${ }^{2}$ Mestre em Engenharia e Gestão do Conhecimento.

${ }^{3}$ Doutora em Engenharia e Gestão do Conhecimento.

${ }^{4}$ Doutora em Engenharia e Gestão do Conhecimento.
} 
Desenvolvimento da Educação surgiu dessa necessidade, de enxergar a educação de uma determinada região de forma sistêmica e inovadora, entendendo que o resultado das partes faz parte de um todo. Nesse sentido no ano de 2015, foi criado o Arranjo de Desenvolvimento da Educação da Grande Florianópolis (ADEGRANFPOLIS), com o intuito de alavancar a qualidade da educação no âmbito municipal e consequentemente no regional. $\mathrm{O}$ arranjo foi fruto de muito diálogo entre municípios, associação e de uma parceria com o Instituto Positivo. A região da Grande Florianópolis é composta por 22 municípios, dos quais atualmente 21 estão engajados na melhoria da qualidade da educação por meio do regime de cooperação intermunicipal. Essas ações vão ao encontro à 431 escolas da rede municipal de ensino e atingem diretamente 5.702 professores e 64.213 alunos da Educação Infantil e Ensino Fundamental Anos Iniciais. As ações dos ADEs, geralmente são direcionadas à Educação Infantil e Ensino Fundamental dos anos iniciais, tendo em vista que essas etapas de ensino ficam sob responsabilidade da esfera municipal, ao menos em sua maioria. Os resultados obtidos nesses primeiros anos do ADEGRANFPOLIS, foram muito positivos. Além de conter a crescente queda do Índice de Desenvolvimento da Educação Básica (IDEB) e corrigir a distorção idade/ano, os municípios da região construíram e revisaram suas leis educacionais, e tiveram a oportunidade de realizar cursos de capacitação para professores, gestores e equipe técnica, alavancando a qualificação dos professores e consequentemente, o ensino da região.

Palavras-chave: Educação, regime de cooperação, arranjo de desenvolvimento da educação.

\section{INTRODUÇÃO}

Nas últimas décadas o mundo vem sofrendo mudanças bruscas em vários segmentos, em questão de pouco tempo, o que era inovador tornou-se obsoleto. Com a educação não é diferente, aquela educação tradicional pautada no unicentralismo do professor ou livro, tornou-se insustentável, o público de dois anos atrás, já não é o mesmo de hoje, o ritmo e as tendências tecnológicas ditam as regras, até mesmo no contexto educacional. 
Diante dessa transformação, no ano de 2016, foi lançado o Movimento Colabora Educação, que tinha como intuito discutir, repensar e entender a realidade e as condições necessárias para melhorar os resultados da aprendizagem, por meio de um trabalho conjunto entre os entes federados, fundações, institutos, grupos e instituições financeiras em vários eixos estratégicos. Um dos eixos estratégicos do movimento é a produção, gerenciamento e transmissão do conhecimento no âmbito educacional, tendo em vista a experiência prática e teórica por meio de um regime de colaboração na educação.

O regime de colaboração está previsto dentro da Constituição Federal e segue os princípios da Lei de Diretrizes e Bases da Educação Nacional de (LDB/96), assim como está de acordo com o Plano Nacional de Educação e referenciado nos planos estaduais e municipais de educação. Esse regime de colaboração ganhou mais visibilidade a partir da criação dos ADEs (Arranjos de Desenvolvimento da Educação).

Para Ramos (2010), os arranjos educacionais foram concebidos como um "modelo de trabalho em rede no qual um grupo de municípios com proximidade geográfica e características sociais e econômicas semelhantes, busca trocar experiências e solucionar conjuntamente dificuldades na área da educação". Nesse sentido, o Arranjo de Desenvolvimento da Educação (ADE) pode ser considerado um modelo de atuação da educação básica em regime de cooperação intermunicipal, que busca por meio de ações conjuntas, ampliar a equidade e melhorar a qualidade educacional dos alunos daquela região em destaque.

De acordo com Abrucio (2017), esses modelos passaram a ganhar força nessa última década, sendo que a primeira experiência de um modelo de regime cooperativo educacional no Brasil, surgiu no ano de 2009. Esse modelo reuniu 12 municípios do recôncavo baiano, com o apoio do Mistério da Educação (MEC), Secretaria de Educação do Estado da Bahia (SEE-BA), União Nacional dos Dirigentes Municipais de Educação da Bahia (UNDIME-BA), Conselho Estadual de Educação da Bahia (CEE-BA), Instituto Votorantim, Movimento Todos pela Educação, Secretária Municipais de Educação e Universidade Federal do Recôncavo Baiano (UFRB). Ainda em 2009, outras duas regiões implantaram modelos semelhantes, um modelo na 
Linha Férrea de Carajás, no Maranhão e outro em Votuporanga, no estado de São Paulo.

No ano de 2010, os ADEs começam a ter maior visibilidade pelo êxito da maioria dos modelos implantados, pelas discussões da CONAE- 2010 (Conferência Nacional de Educação) e pelo encaminhamento do Projeto de Lei que trata sobre a inserção dos arranjos educativos no Plano Nacional e na legislação educacional. Esse projeto foi encaminhado ao Congresso pelo deputado Alex Canziani, tendo sua aprovação no ano seguinte, por meio da homologação do Parecer CNE/CEB no 09/2011, que criou um grupo de trabalho, pela Portaria ํㅡ 1.238, de 11 de outubro de 2012, para elaborar estudos sobre a implementação do regime de colaboração na forma de ADEs.

A inserção dos arranjos educacionais ocorreu somente em 25 de junho de 2014, por meio do $\S 7^{\circ}$ do Artigo $7^{\circ}$ da Lei ํㅜ 13.005 , que aprova o Plano Nacional de Educação: "O fortalecimento do regime de colaboração entre os Municípios dar-se-á, inclusive, mediante a adoção de arranjos de desenvolvimento da educação" (BRASIL, 2014, p. 46).

Em julho de 2015, o MEC (Ministério da Educação) publica o relatório final do grupo de trabalho que ficou responsável pelo estudo da implantação e acompanhamento dos ADEs, apresentando muitos pontos que deveriam ser revistos, entre eles, a falta de transparência ou inexistência dos mecanismos de financiamento, aprimoramento da promoção entre os entes federados, testando, desenvolvendo e melhorando os dispositivos de cooperação intermunicipal, e por fim, trabalhar na possibilidade do repasse do fundo de educação, levando em consideração a aderência e os resultados dos ADEs.

\section{ADE - GRANFPOLIS}

O ADE- GRANFPOLIS, foi consolidado no ano de 2015, entretanto, o regime de colaboração da região, existia antes mesmo da criação do ADE - GRANFPOLIS. Os municípios por meio da Associação dos Municípios da GRANFPOLIS, reuniam-se 
periodicamente para discutir ações administrativas e pedagógicas visando a melhoria na qualidade da educação da região.

O ADE- GRANFPOLIS foi fruto de muito diálogo entre municípios, associação e possíveis colaboradores, sendo que após algumas reuniões os municípios firmaram uma parceria com o Instituto Positivo, que continua até hoje atuando diretamente nas ações e estratégias elencadas pelo grupo.

A região da Grande Florianópolis é composta por 22 municípios, dos quais atualmente 21 estão engajados na melhoria da qualidade da educação por meio do regime de cooperação intermunicipal. Essas ações vão de encontro à 431 escolas da rede municipal de ensino e atingem diretamente 5.702 professores e 64.213 alunos da Educação Infantil e Ensino Fundamental Anos Iniciais. As ações dos ADEs. Geralmente são direcionadas à Educação Infantil e Ensino Fundamental Anos Iniciais, tendo em vista que essas etapas de ensino ficam sob responsabilidade da esfera municipal, ao menos em sua maioria.

\section{PLANO DE AÇÃO DO ADE - GRANFPOLIS}

De acordo com dados do relatório do ADE- GRANFPOLIS e Instituto Positivo, divulgado na Revista de Resultados (2017), durante as discussões do arranjo, no ano de 2015 , foram elencadas quatro metas que deveriam ser estudadas e consolidadas até o término da primeira fase do ADE, no caso, final do ano de 2017. Essas metas tiveram como base o Plano Nacional de Educação e os Planos Municipais de Educação. O Plano Municipal de Educação, já foi construído em uma linha de regime de cooperação pelos municípios da Grande Florianópolis.

A primeira meta tinha como objetivo instituir, implementar e consolidar, um processo de avaliação em larga escala com abrangência de 100\% dos municípios que compõem o ADE da GRANFPOLIS, o objetivo principal dessa avaliação é compreender os motivos reais da não aprendizagem, da retenção e evasão escolar durante o Ensino Fundamental. Ela foi desenvolvida com base nos resultados de um diagnóstico realizado com a participação dos municípios da Grande Florianópolis, 
Associação da GRANFPOLIS e Instituto Positivo. O diagnóstico apresentou, que 19\% dos Sistemas de Ensino baixaram a nota de 2013 em relação à nota de 2011; 91\% dos Sistemas de Ensino que tem nota no IDEB dos Anos Finais não atingiu a meta em 2013; 70\% dos Sistemas de Ensino que ofertam os Anos Finais têm taxa de reprovação maior que $15 \%$, junto às turmas do 6ํano; $86,3 \%$ dos Sistemas de Ensino que ofertam os Anos Finais registram reprovação em todas as turmas dessa etapa de ensino; $63,5 \%$ dos Sistemas de Ensino do ADE da GRANFPOLIS registram o maior índice de reprovação dos Anos Iniciais do Ensino Fundamental no 3ํano.

Nesse sentido foi criado uma avaliação subsidiada pelo Instituto Positivo, para mensurar e diagnosticar não somente os alunos, mas também a didática e metodologia dos docentes.

A segunda meta tinha como objetivo, melhorar o fluxo escolar junto a todas as turmas do Ensino Fundamental na região do ADE-GRANFPOLIS, reduzindo até o ano de 2017, a taxa atual média geral de distorção idade/ano e por meio de uma reorganização curricular e didático-pedagógica, sanar as dificuldades de aprendizagem. O diagnóstico dessa meta, apresentou os seguintes resultados: 100\% dos Sistemas de Ensino registram distorção idade/série atingindo, em 2014, aproximadamente, 13.700 estudantes do território do ADE da GRANFPOLIS, segundo dados do Censo Escolar/2014 divulgado pelo Inep. A taxa média de distorção idade/série no $9^{\circ}$ ano na área rural é 45,5 e na área urbana é de 36,8. A taxa média de distorção idade/série dos anos finais é $160 \%$ maior que a dos anos iniciais do Ensino Fundamental; 70\% dos Sistemas de Ensino que ofertam os Anos Finais têm taxa de reprovação maior que 15 , junto às turmas do $6^{\circ}$ ano e $86,3 \%$ dos Sistemas de Ensino que ofertam os Anos Finais registram reprovação em todas as turmas dessa etapa de ensino.

É importante explicitar que para a consolidação da segunda meta o ADEGRANFPOLIS, contou com a parceria do Instituto Positivo e com o importante apoio do Instituto Ayrton Senna, que nos ofertou programas de alfabetização e correção de fluxo. 
A terceira meta tinha como objetivo, elaboração de documento de propostas de aplicação dos recursos do FUNDEB e valorização dos Profissionais da Educação, com implementação de $1 / 3$ de hora atividade para todos os professores que atuam na região do ADE-GRANFPOLIS, independentemente do nível, etapa ou modalidade de ensino.

O diagnóstico referente à terceira meta, apresentaram que $68 \%$ dos Sistemas de Ensino utilizam mais de $80 \%$ do FUNDEB na remuneração dos Profissionais do Magistério em efetivo exercício; $54,5 \%$ dos Sistemas de Ensino do ADE GRANFPOLIS aplicam menos de $10 \%$ de recursos do FUNDEB com demais despesas com a manutenção e desenvolvimento do ensino; 95,4\% dos Sistemas de Ensino do ADE - GRANFPOLIS ainda não implantaram $1 / 3$ de hora atividade junto a todos os níveis/etapas e modalidades de ensino, segundo dados do próprio ADE GRANFPOLIS, com apoio do Instituto Positivo.

Essa meta foi muito discutida pelo grupo, a maioria dos municípios que fazem parte do ADE- GRANFPOLIS criaram leis regulamentando o $1 / 3$ de hora atividade, assim como, a implantação do Sistema de Ensino e a revisão do Plano de Carreira do Profissional Docente, entretanto, muitos estão enfrentando a dificuldade de orçamento para poder cumprir a lei, tendo em vista que o FUNDEB não é suficiente para o pagamento dos profissionais e que uma fatia bem gorda do recurso próprio do município é destinada para o pagamento dos docentes. É relevante dizer que essa meta ainda está em discussão e frequentemente são desenvolvidas ações para amenizar esse impacto financeiro.

A quarta meta tem como objetivo, criação de uma avaliação institucional para diagnosticar e avaliar as ações dos Sistemas Municipais de Ensino. O diagnóstico dessa quarta meta apresenta que $70,54 \%$ dos profissionais que atuam nas Secretarias Municipais de Educação dos Sistemas de Ensino do ADE - GRANFPOLIS em 2015, não tem cargo efetivo nas Secretarias; $74,4 \%$ dos Sistemas de Ensino não têm critérios para a escolha de direção de escolas; 96\% das escolas de Educação Infantil dos Sistemas de Ensino do ADE - GRANFPOLIS não têm Biblioteca, nem Sala de Leitura. 
Essa quarta meta é uma das mais amplas, ela trata da gestão e administração escolar, mas com o apoio da gestão pública para desenvolver trabalhos conjunto entre escola, setor público e sociedade. Nessa meta foram realizados cursos e capacitações para gestores e equipe técnica para tratar de assuntos administrativos e pedagógicos, o destaque foi o curso de capacitação dos Gestores em Movimento.

As quatro metas detalhadas anteriormente foram aplicadas entre os anos de $2015 \mathrm{e}$ 2017, entretanto, foram realizados trabalhos paralelos entre os anos de 2013 e 2014 , porém de forma superficial e sem a adesão de todos municípios da região.

Portanto, o resultado da ação do arranjo de forma numérica será apresentado somente com os resultados do IDEB, que provavelmente será divulgado no mês de setembro do corrente ano. Entretanto, cabe ressaltar a atual importância do arranjo para com os municípios, por meio das ações todos os municípios da região construíram suas leis educacionais especificas, além disso, tiveram a oportunidade de corrigir a defasagem idade/ano e realizar cursos de capacitação para professores, gestores e equipe técnica.

\section{METODOLOGIA}

A presente pesquisa assumiu características de estudo qualitativo, foi realizada por meio de investigação bibliográfica e pesquisa e análise na base de dados do IDEB (Índice de Desenvolvimento da Educação Básica) e índices do ADEGRANFPOLIS. De acordo com Araújo (2003, p. 58), o termo "pesquisa" diz respeito a uma classe de atividades cujo objetivo é desenvolver ou contribuir para o conhecimento generalizável.

A investigação bibliográfica apresenta um referencial teórico com base em livros, documentos e artigos publicados relacionados ao regime de cooperação intermunicipal no desenvolvimento da Educação e pela coleta de dados por meio de tabelas, gráficos e quantitativos numéricos, sendo esses, resultados das ações e estratégias desenvolvidas pelo ADE- GRANFPOLIS. 
Para a obtenção dos dados e a elaboração dos gráficos, tabelas e índices foram realizadas pesquisas na base de dados do IDEB (Índice de Desenvolvimento da Educação Básica), entre os anos de 2007 a 2017 e os índices do ADE- GRANFPOLIS, foram analisados desde sua criação em 2015 até 2019, data dos últimos índices.

O IDEB, é um indicador criado pelo governo federal e utilizado para mensurar a qualidade de ensino da educação básica. Seu cálculo é realizado por meio de rendimento (aprovação e reprovação), distorção idade/ano e avaliação dos alunos de dois em dois anos. O indicador foi criado em 2007 pelo INEP (Instituto Nacional de Estudos e Pesquisas Educacionais Anísio Teixeira) no âmbito do Plano de Desenvolvimento da Educação. É relevante explicitar, que foram utilizados os dados do IDEB somente até 2017, pois o indicador de 2019, ainda não se encontra disponível para pesquisa.

\section{RESULTADOS DAS AÇÕES DO ADE - GRANFPOLIS}

Ao analisar os indicadores apresentados na Tabela 1, pode-se evidenciar o crescimento do Índice de Desenvolvimento da Educação Básica de Santa Catarina de 2007 até 2017. Entretanto, será enfatizado os indicadores após o ano de 2013, pois a partir dessa data, a região da Grande Florianópolis por meio da associação dos municípios tornou-se mais atuante por meio do regime de cooperação intermunicipal.

Tabela 1: IDEB 2007, 2013 e 2017 - Municípios da Grande Florianópolis

\begin{tabular}{|l|l|l|l|}
\hline MUNICÍPIO & IDEB 2007 & IDEB 2013 & IDEB 2017 \\
\hline Águas Mornas & 5.8 & 6.0 & 6.7 \\
\hline Alfredo Wagner & 4.6 & 6.0 & 6.9 \\
\hline Angelina & 5.2 & 6.3 & 7.7 \\
\hline Anitápolis & 4.7 & 5.4 & 5.5 \\
\hline Antônio Carlos & 5.6 & 6.9 & 6.6 \\
\hline Biguaçu & 4.2 & 5.0 & 5.5 \\
\hline Canelinha & 5.0 & 6.3 & 6.3 \\
\hline Florianópolis & 4.6 & 5.6 & 5.8 \\
\hline
\end{tabular}




\begin{tabular}{|c|c|c|c|}
\hline Garopaba & 4.6 & 6.3 & 7.1 \\
\hline Governador Celso Ramos & 4.5 & 5.5 & 6.3 \\
\hline Leoberto Leal & - & - & 5.9 \\
\hline Major Gercino & - & - & 6.8 \\
\hline Nova Trento & 5.2 & 6.2 & 6.7 \\
\hline Palhoça & 4.4 & 5.3 & 5.7 \\
\hline Paulo Lopes & 4.4 & 4.4 & 5.7 \\
\hline Rancho Queimado & 4.6 & - & 6.4 \\
\hline $\begin{array}{l}\text { Santo Amaro da } \\
\text { Imperatriz }\end{array}$ & 4.8 & 6.1 & 6.1 \\
\hline São Bonifácio & 4.6 & 6.1 & 6.8 \\
\hline São João Batista & 5.1 & 6.3 & 6.3 \\
\hline São José & 4.4 & 5.3 & 6.2 \\
\hline São Pedro de Alcântara & 5.3 & 6.8 & 6.8 \\
\hline Tijucas & 4.5 & 5.6 & 5.9 \\
\hline
\end{tabular}

Fonte: Elaborado pelos autores com base no Índice de Desenvolvimento da Educação Básica (IDEB 2017).

No ano de 2013, a média do IDEB brasileiro foi de 5.8 e a média catarinense de 5.9, assim como a média da região da Grande Florianópolis. Já no ano de 2017, a média nacional continuou em 5.8, entretanto, o estado de Santa Catarina avançou para 6.3 e a região da Grande Florianópolis teve um índice ainda melhor 6.4. Sendo que 10 dos 22 municípios tiveram um IDEB acima de 6.5, dos quais 08 municípios tiveram seus índices maiores ou iguais a 6.7, uma média excelente.

Em depoimento na Revista Resultados 2017, o líder do ADE-GRANFPOLIS Antão Antônio David (2017) ressalta a importância do arranjo da região da Grande Florianópolis. "Nós conseguimos, com o Arranjo, mudar todas as perspectivas da Educação: as crianças, os professores, toda a gestão das Secretarias Municipais de Educação estão tendo uma grande transformação para melhor". 
Para o ano de 2019, cria-se uma expectativa ainda maior, referente a média do IDEB da região da Grande Florianópolis, pois foram desenvolvidas várias estratégias e ações, enfatizando o processo de alfabetização, leitura e interpretação de textos, além das formações de professores, equipe técnica, coordenadores e gestores. Essas ações vão ao encontro de 21 secretárias de educação municipal e contribuíram diretamente na melhoria da qualidade do ensino de 64.213 alunos da Educação Infantil e Ensino Fundamental Anos Iniciais.

\section{CONSIDERAÇÕES FINAIS}

Diante das várias dificuldades enfrentadas pelo atual cenário da educação brasileira, os ADEs apresentam ações em regime de colaboração, com ênfase no modelo de cooperação intermunicipal. Dessa forma, intensificando a qualidade das relações entre os municípios parceiros pode-se ampliar a equidade e qualidade da educação.

A cooperação intermunicipal evidenciada no ADE- GRANFPOLIS, nos apresenta resultados significativos, todos os municípios estão fortemente engajados em ações que possam contribuir diretamente em seu próprio município e assim, também contribuir com os demais municípios de forma conjunta.

A expectativa torna-se ainda maior, ao aguardar os resultados IDEB do ano de 2019, pois foram desenvolvidas várias estratégias e ações, enfatizando o processo de alfabetização, leitura e interpretação de textos, além das formações de professores, equipe técnica, coordenadores e gestores. Todas essas ações irão impactar de forma positiva no índice, muito provavelmente mantendo ou elevando a pontuação dos municípios da região.

\section{REFERÊNCIAS}

ABRUCIO, Fernando L; Cooperação Intermunicipal: experiência de Arranjo de Desenvolvimento da Educação no Brasil. 1ํㅡㄹ ed. Curitiba: Positivo, 2017. p. 85. 
ADE-GRANFPOLIS; Instituto Positivo. Históricos e Metas. Revista de Resultados 2017. Disponível em: <http://institutopositivo.org.br/wp-content/uploads/2020/02/ADEGRANFPOLIS-\%E2\%80\%93-RESULTADOS-2017.pdf> Acesso em:17 de set. 2020.

ARAÚJO, Laís Záu Serpa de. Aspectos éticos da pesquisa científica. Pesquisa Odontológica Brasileira, [S. I.], v. 17, n. 1, p. 57-63, 2003.

BRASIL. Plano Nacional de Educação 2014 - 2024. Disponível em: <http://www.proec.ufpr.br/download/extensao/2016/creditacao/PNE\%2020142024.pdf> Acesso em 06 de jun. de 2020.

INEP (Instituto de Estudo e Pesquisas Educacionais Anísio Teixeira). IDEBResultados e Metas. Disponível em: <http://ideb.inep.gov.br/resultado/> Acesso em: 10 jun. 2020.

RAMOS, M. N. Arranjos de Desenvolvimento de Educação. In: ABRUCIO, F. L.; RAMOS, M. N. (Orgs). Regime de colaboração e associativismo territorial: arranjos de desenvolvimento da educação. São Paulo: Fundação Santillana, 2012, p. 67-84.

Enviado: Setembro, 2020.

Aprovado: Setembro, 2020. 